\title{
CALCULATION AND EXPERIMENTAL VERIFICATION OF RESIDUAL STRESSES IN RIVETED JOINTS USED IN AN AIRFRAME
}

\author{
Elżbieta Gadalinska \\ Wojciech Wronicz \\ Jerzy Kaniowski \\ Bartosz Korzeniowski
}

Institute of Aviation, Warsaw, Poland

\begin{abstract}
This paper presents diffraction measurements of residual stresses around the rivet, formed during the riveting process. The measurements were made with the XSTRESS-3000 diffractometer, manufactured by Stresstech Oy. The measurements were carried out on specimens made of bare sheet 2024-T3 alloy, (standard AMS-QQ-250 / 4). The measurement results were compared with the FEM simulation results.
\end{abstract}

The work was performed under the EUREKA IMPERIA project E! 3496.

\section{INTRODUCTION}

Fatigue is one of the most important factors affecting functional properties of aircraft. Fatigue life is crucial in the stress concentration areas, where fatigue cracks are usually initiated. In most metal airframes stress concentrators are related to joints between elements. The most common technique for joining metal airframe is riveting. In a typical aviation structures there are between several thousands and several millions rivets, depending on the size of the aircraft. The most important factor affecting the fatigue life of riveted joints is the state of residual stresses formed in the joined elements during the riveting process (manually or press riveted). As shown by Müller [1], one can effectively influence the state of residual stresses by controlling the squeezing force during the riveting process.

Enlarging the rivet squeezing force results in better filling of the rivet hole, an increase of clamping between the linked plates allowing transfer of loads by friction, and also creating a driven head of a larger diameter.

Fatigue cracks of structural components of aircraft are results of operating tensile stress. When considering riveted joints, circumferential stresses occurring in the joined elements near the rivets play a crucial role. The stress field around the rivet is the result of stresses generated during riveting (and other processes) and the stress occurring during the operation. At low and mediumsized squeezing forces, while squeezing the rivet shank, the radial compressive stresses and tensile circumferential stresses are formed in the sheet plate. Increased squeezing force will change sign in the circumferential stresses in linked elements in the immediate surroundings of the rivet - from tensile to compressive. As a result, tensile stresses occurring during operation are reduced by compressive stresses introduced during the riveting process, which increases fatigue life. 


\section{IMPLEMENTATION OF RIVETED SPECIMEN}

In order to investigate the feasibility of introducing compressive stress by increasing the squeezing force, the measurements of residual stresses on the sheet plate surface surrounding the rivet were carried out. 13 specimens were performed according to the geometry shown in Fig. 1. In the specimens, four fields were separated, in which fixed squeezing forces were used, so that the ratio of diameter $\mathrm{D}$ of driven head to rivet diameter $\mathrm{d}$ was $1.2,1.4,1.5,1.55$ respectively in fields $1,2,3$ and 4.

The paper will present the results of measurements for the diameter of $3 \mathrm{~mm}$ mushroom head rivet made of PA25 alloy, in accordance with the Polish industry standard BN-70/1121-06. The specimens were made of bare 2024-T3 alloy sheet (American Standard AMS-QQ-250/4) of the nominal thickness of $1.27 \mathrm{~mm}$. The package consists of two sheets. The actual thickness of the package is $2.55 \mathrm{~mm}$. The specimens were made by PZL Mielec (Polish Aviation Factory). Rivets marked were squeezed on the press by the device shown in Fig. 4b, in accordance with the factory riveting instructions. Then the $\phi$ marked holes were performed as "ready-made" (prepared for the rivet insertion and riveting). Their diameters were measured and recorded in the table of measurements (Fig. 2). Before riveting the test specimen, in a special series of tests for each type of rivet set, the dependence between the ratio of the diameter of driven head to rivet diameter $\mathrm{D} / \mathrm{d}$ and the size of squeezing force was determined (Fig. 3).

Rivets in the rivet holes marked $\phi$ were squeezed on the INSTRON testing machine able to control the squeezing force (the force that squeezes the rivet shank) - Fig. 4a - using the set for riveting shown in Fig. 4b. Before riveting subsequent rivets, measurements of their diameter and length were carried out, and saved in the appropriate fields of the measurements table (Fig. 2). For each rivet in fields 1 to 4 , during squeezing, the movement of the piston of the testing machine was controlled and the squeezing force was recorded continuously. The process was interrupted after reaching the required value of the squeezing force and the piston actuator was raised. To study the distribution of residual stresses, the rivets for which the registered squeezing force value was closest to the required value were chosen. The squeezing force distribution for rivet 18 is shown in fig. $3 b$.

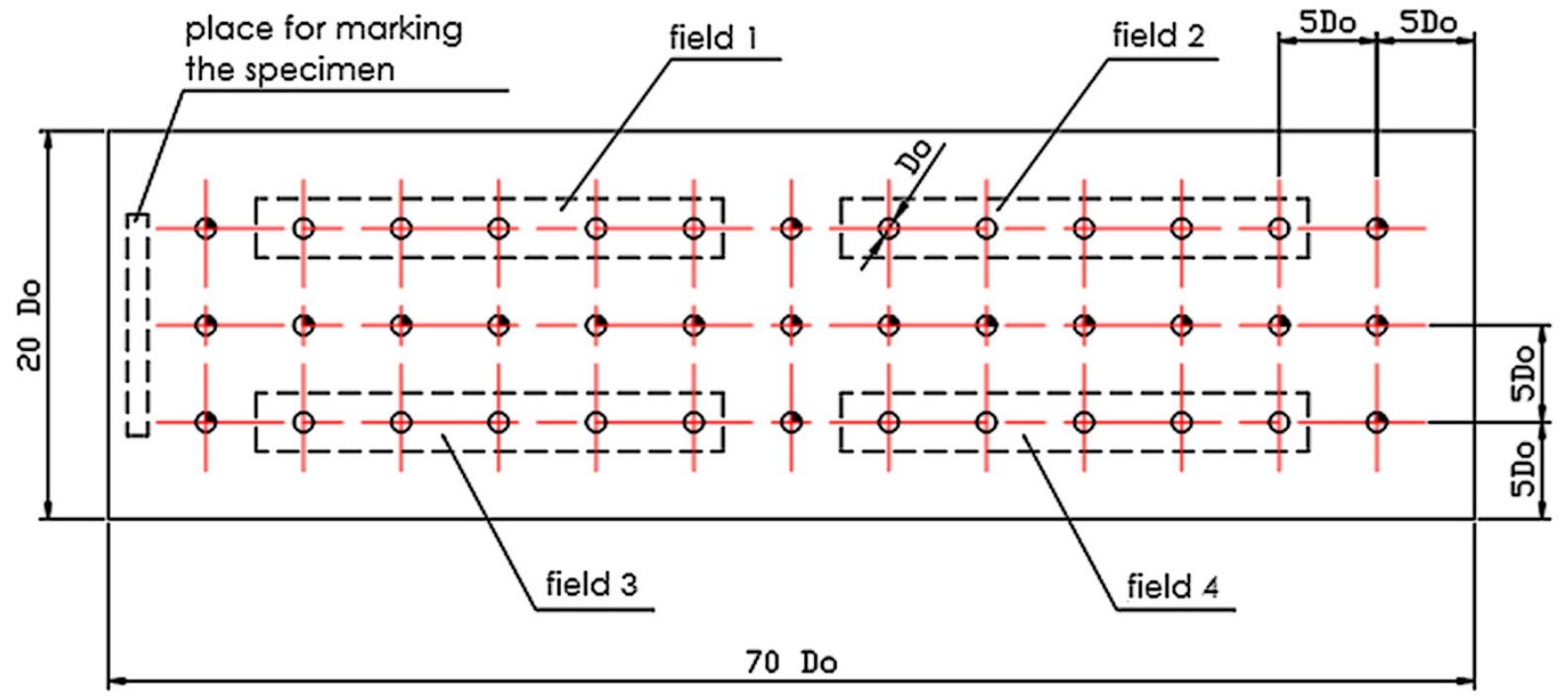

Fig. 1. Drawing of series of WP6.1 specimen 


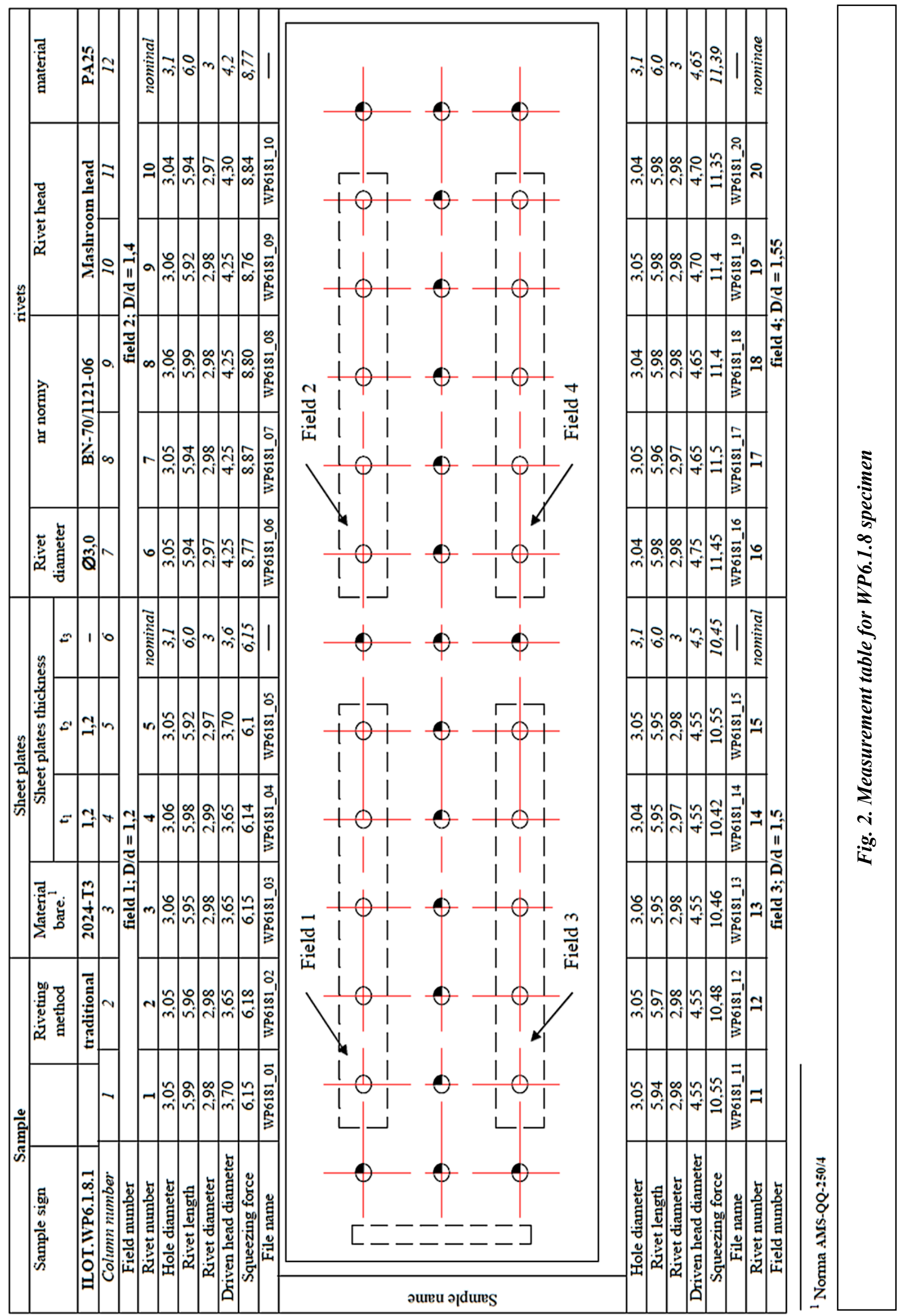




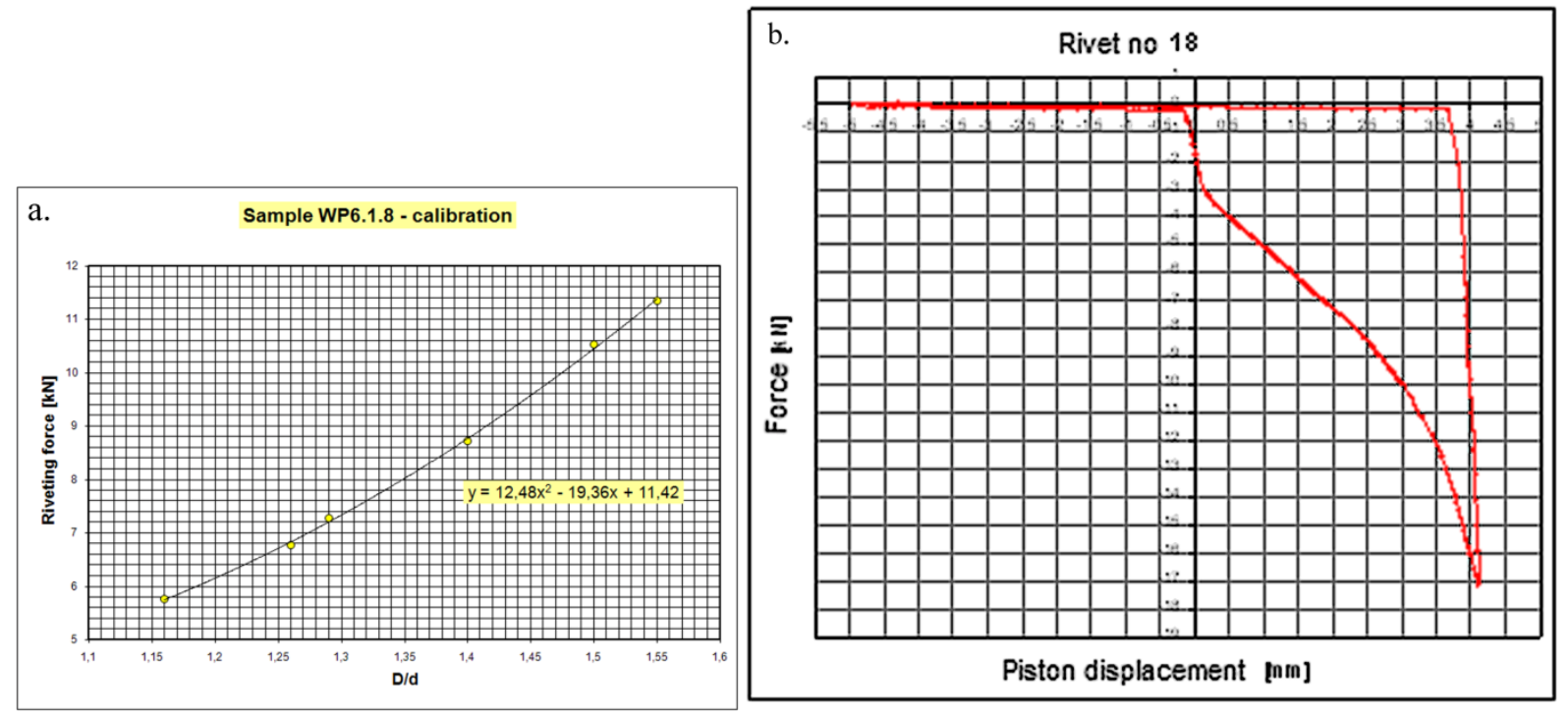

Fig. 3. Relation between driven head diameter to rivet diameter ratio D/d and squeezing force (a) and recorded squeezing force course

a.
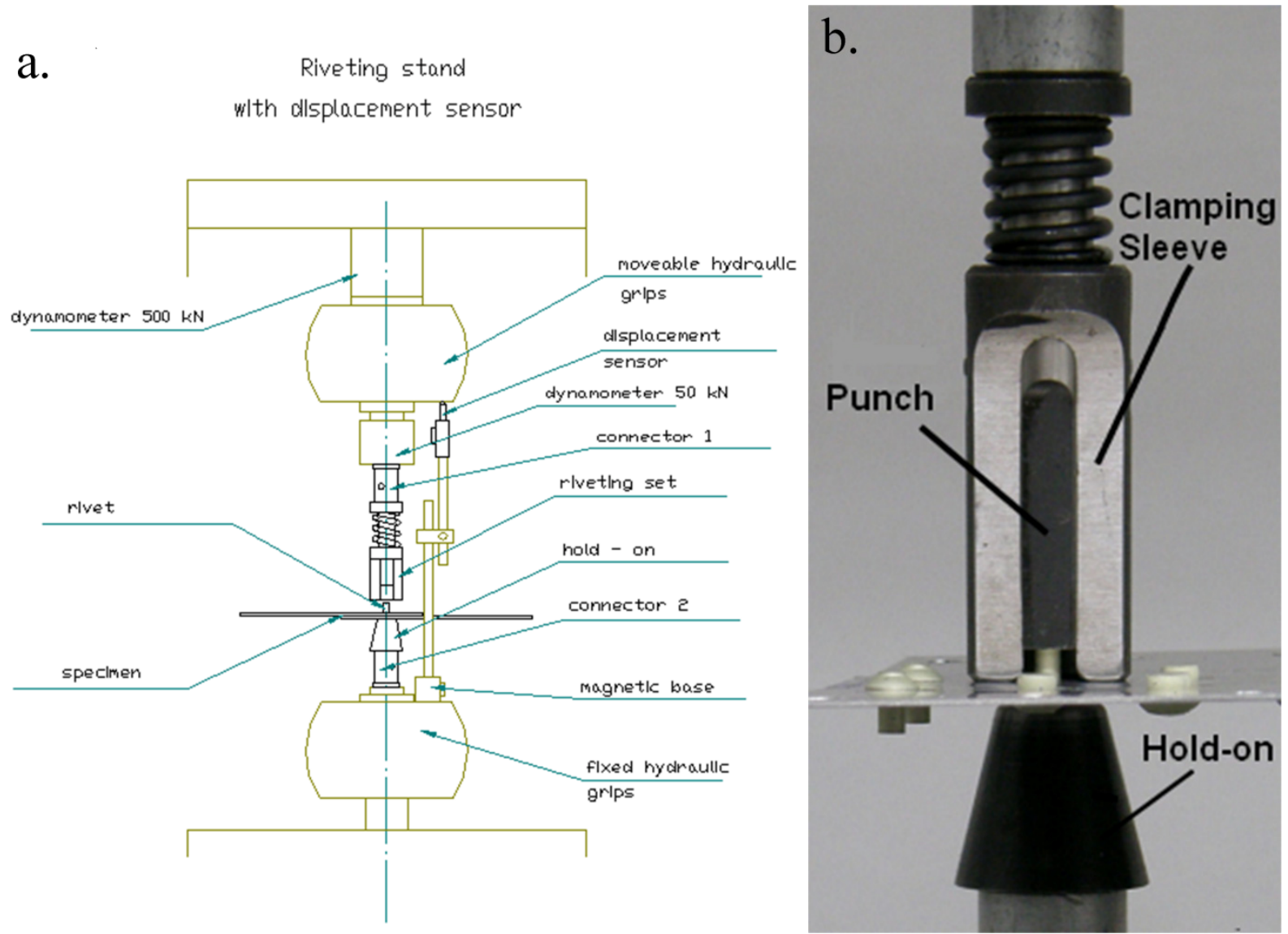

Fig. 4. Riveting stand on testing machine. a) scheme of the stand [2]

b) riveting set (on the basis of [3]) 


\section{X-RAY DIFFRACTOMETRY RESIDUAL STRESS MEASUREMENTS IN RIVETED JOINT}

Measurements of residual stresses were performed using the X-ray diffractometer XSTRESS 3000, produced by Stresstech Oy. The device XSTRESS 3000 is equipped with a computer controlled measuring table, which allows measuring at pre-programmed measuring points, Fig. 5. For WP6.1.8 specimen (in Fig. 5 located further in the picture), measurements were taken in the surrounding of rivets $3,6,13$ and 18 , which can be found in fields $1,2,3$ and 4 . For each rivet, there were two measuring segments drawn, the one parallel to the length of the specimen (sheet rolling direction) and the other perpendicular to it. For each of these segments, there were two measurements conducted at eight points: one of radial stress (along the segment) and the other of circumferential stress (perpendicular to the segment). The measurement parameters are presented in Table 1, the angles occurring in the measurement are marked in Fig. 6.

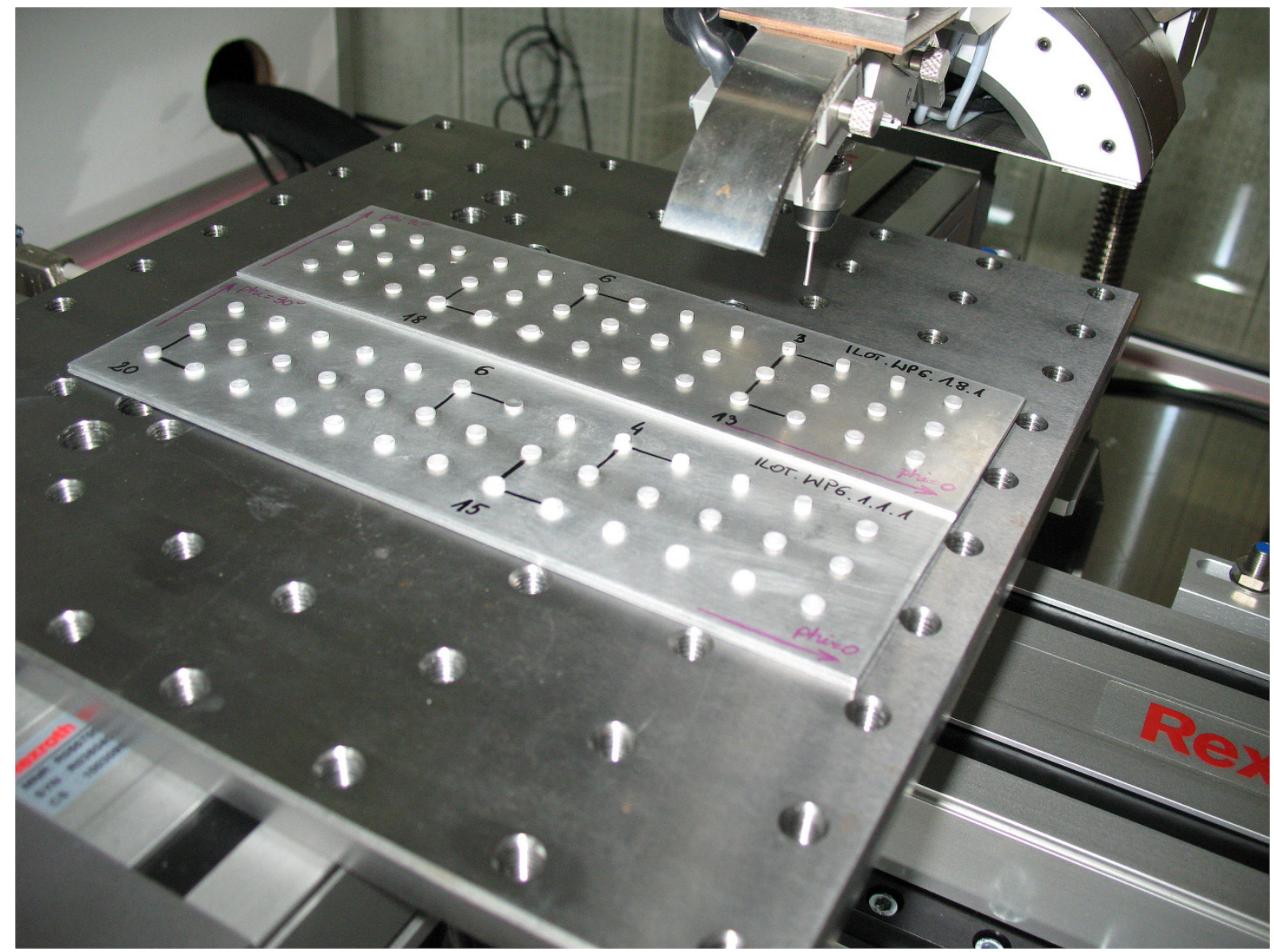

Fig. 5. Residual stress measurements in rivet vicinity on WP6.1.8 specimen 


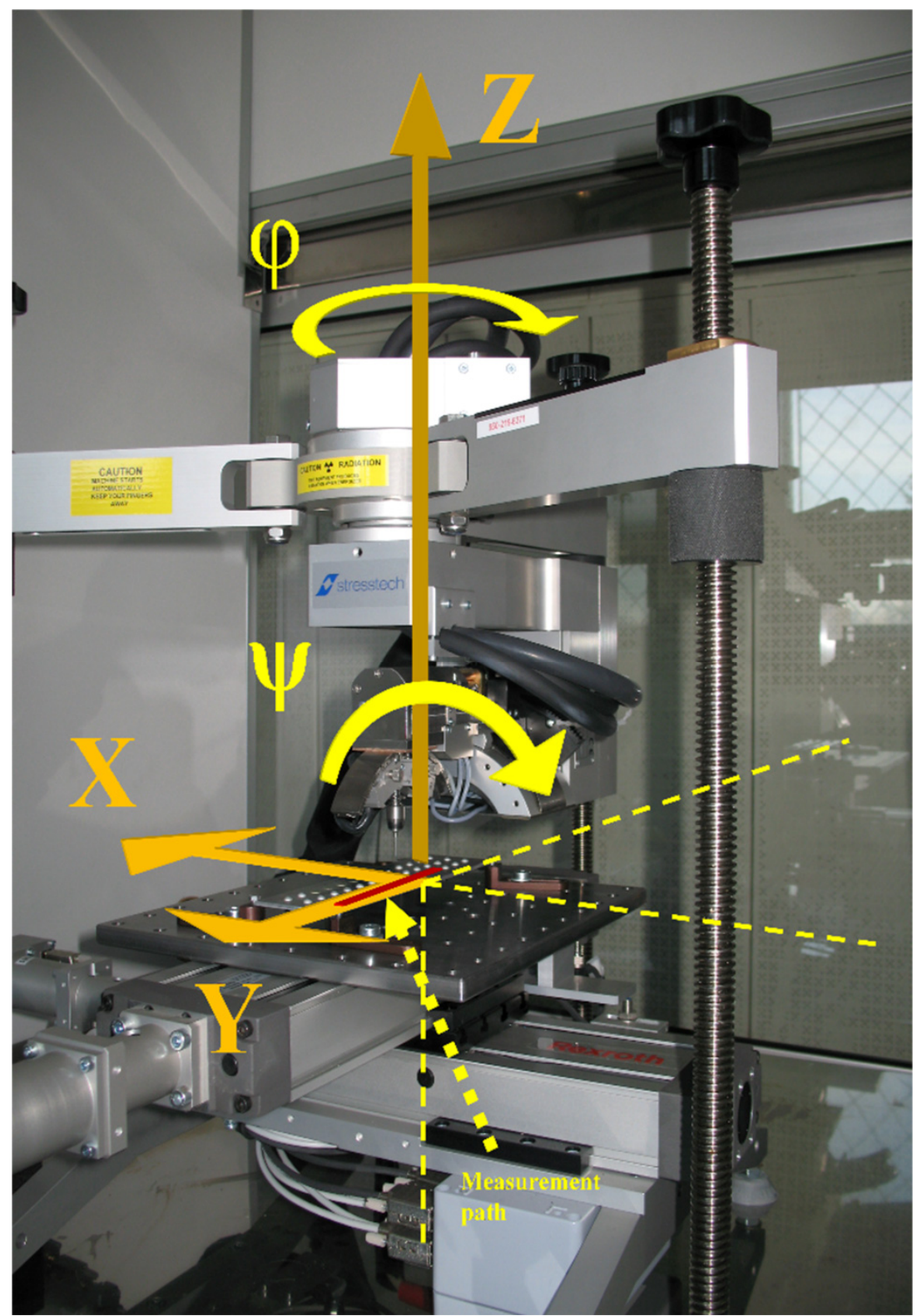

a)

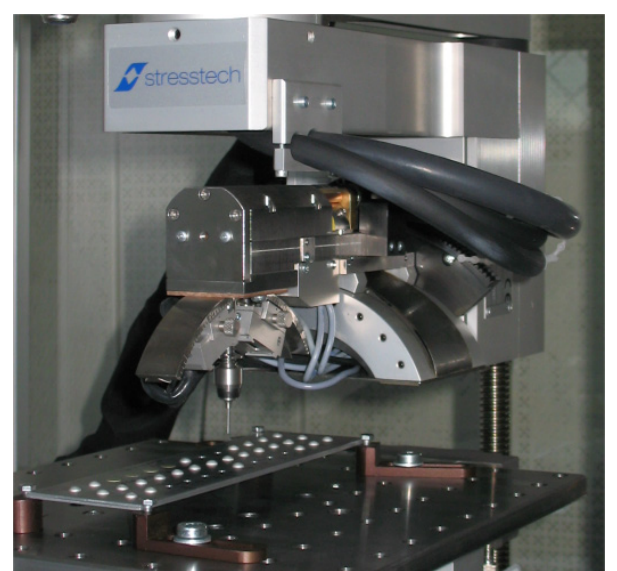

b)

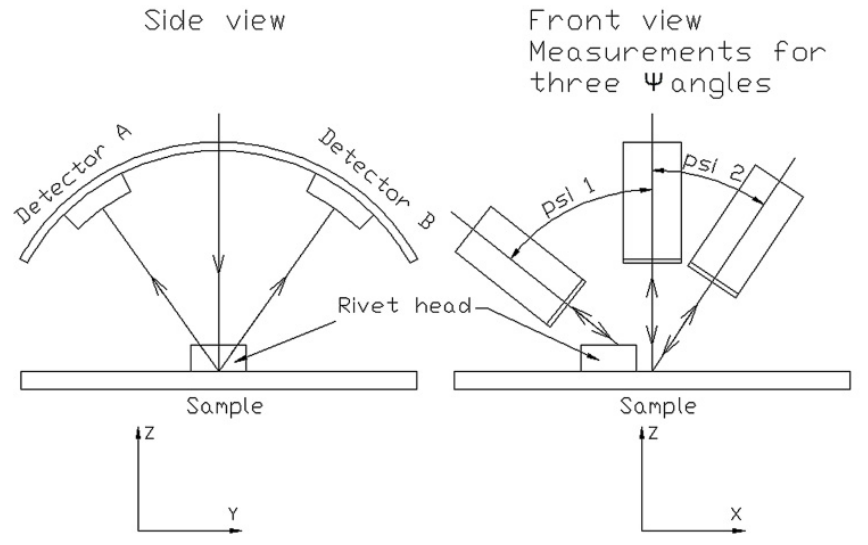

c)

Fig. 6. Measurements geometry 
Tab. 1. Diffractometric measurements parameters

\begin{tabular}{|l|l|l|}
\hline Measurement date: & & VII.2009 \\
\hline \multirow{5}{*}{ Calculations: } & 2theta & Biblioteka \\
& Background & Liniowa \\
& A i B \\
no \\
& Detectors & Cross corr. \\
\hline Collimator distance: & Peak displacement & $9.45 \mathrm{~mm}$ \\
\hline \multirow{3}{*}{ Material data: } & d & Al $(2024)$ \\
& Material & $70600 \mathrm{MPa}$ \\
& Y - modulus (E) & $42.71 / \mathrm{mm}$ \\
& Absorption factor $\mu$ & 0.33 \\
\hline \multirow{5}{*}{ Measurement parameters: } & Poisson ratiov & $156,7^{\circ} / 222^{\circ}$ \\
& $2 \Theta / h k 1$ & $60 \mathrm{~s}$ \\
& Exposure time & Psi \\
& Mode & 0,90 \\
& $\varphi$ & $5^{\circ} / 3$ \\
& $\varphi$ oscillations & $10 / 10$ \\
& $\psi$ & $-39^{\circ} / 39^{\circ}$ \\
& $\psi$ oscillations & CrKa \\
\hline Collimator type: & Radiation & $0,8 \mathrm{~mm}$ \\
\hline
\end{tabular}

Analyzing the geometry of measurement, it was found that for the angle $\Psi=39^{\circ}$ the driven head obscures the point of measurement, as shown in Fig. 7. In the case of rivet 3, the obscuration occurs for the measuring point 1 , the nearest to the driven head, as shown in Fig. 7b. This leads to a significant distortion of measurements for measuring points 1 and 2 . While computing the residual stress these $\Psi$ angle measurements were rejected, for which the covering of measurement field is taking place.

The values of residual stresses computed this way are shown in Fig. 8. Table 2 summarises the results of measurements before and after correction.

a.
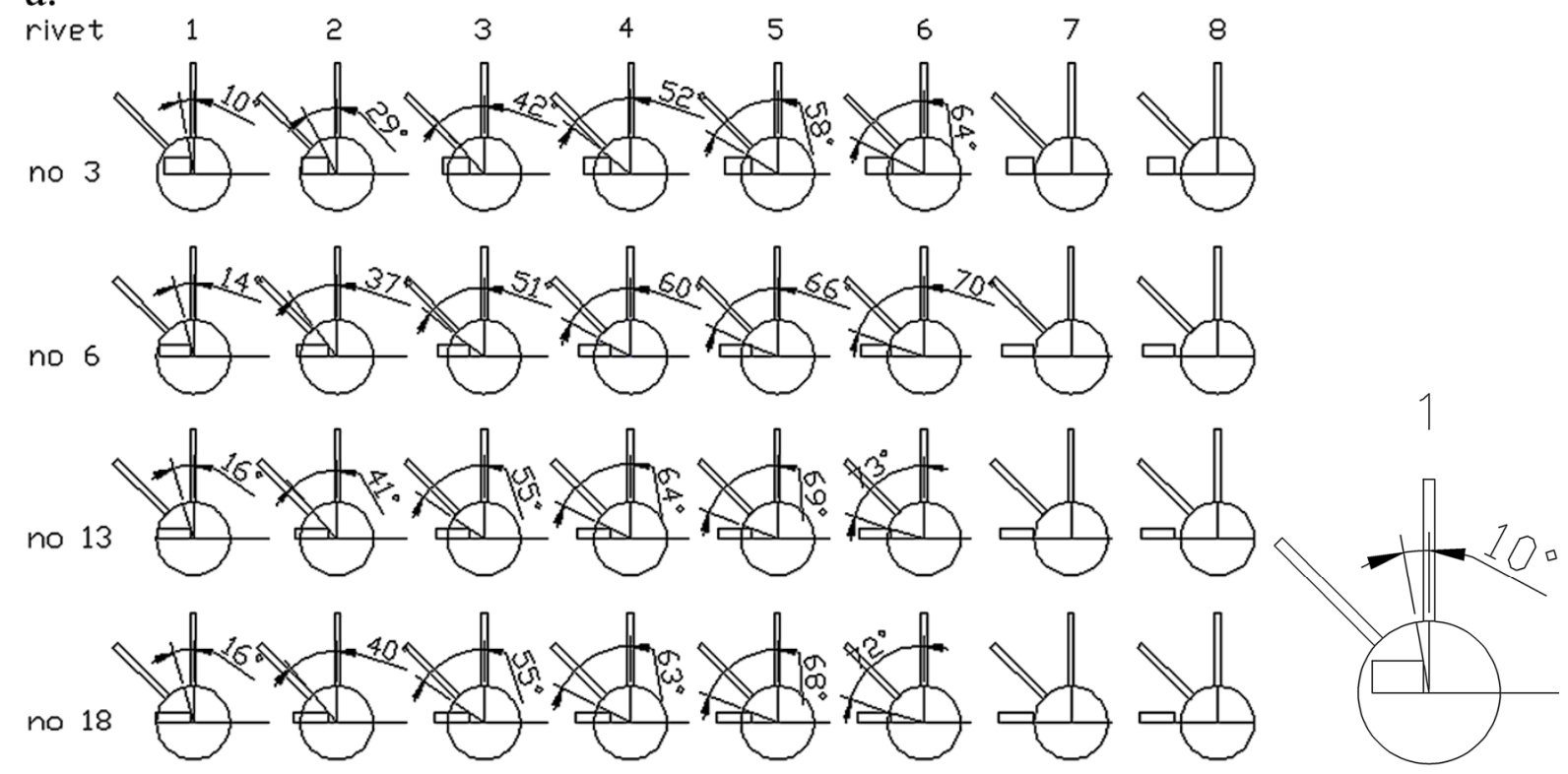

Fig. 7. Driven head shadow analysis 
Tab. 2. Residual stress measurements results

\begin{tabular}{|c|c|c|c|c|c|c|c|c|}
\hline \multirow{5}{*}{ No } & \multicolumn{2}{|c|}{ Measuring point } & \multicolumn{6}{|c|}{ Residual stress [MPa] - measurement results } \\
\hline & \multirow{3}{*}{$\begin{array}{l}\text { Absolute } \\
\text { position }\end{array}$} & \multirow{3}{*}{$\begin{array}{l}\text { Relative } \\
\text { position }\end{array}$} & Befor & rrection & \multicolumn{2}{|c|}{ After correction } & & \\
\hline & & & \multicolumn{6}{|c|}{ phi angle- measured relatively to measurement segment } \\
\hline & & & \multicolumn{2}{|c|}{$0^{\circ}$ - radial } & \multicolumn{2}{|c|}{$0^{\circ}$ - radial } & \multicolumn{2}{|c|}{$90^{\circ}$ - circumferential } \\
\hline & \multirow[t]{2}{*}{$\mathrm{mm}$} & \multirow[t]{2}{*}{$\mathrm{r} / \mathrm{R}$} & $\sigma$ & $\Delta \sigma$ & $\sigma$ & $\Delta \sigma$ & $\sigma$ & $\Delta \sigma$ \\
\hline & & & \multicolumn{6}{|c|}{ Rivet 3_I - measurement segment parallel to longer edge of specimen } \\
\hline 1 & 0,4 & 1,48 & $-218,5$ & 14,9 & $-215,6$ & 14,7 & $-13,2$ & 52,7 \\
\hline 2 & 1,2 & 2,01 & $-135,9$ & 21,1 & $-236,0$ & 121,2 & 77,0 & 9,5 \\
\hline 3 & 2 & 2,55 & $-111,5$ & 10,1 & $-109,8$ & 13 & $-10,7$ & 9,3 \\
\hline 4 & 2,8 & 3,09 & $-58,3$ & 12,4 & $-57,5$ & 12,3 & 25,9 & 13,5 \\
\hline 5 & 3,6 & 3,62 & $-87,6$ & 9,5 & $-86,5$ & 9,4 & $-3,2$ & 8,7 \\
\hline 6 & 4,4 & 4,16 & $-90,1$ & 15,9 & $-88,9$ & 15,7 & $-27,1$ & 12,7 \\
\hline 7 & 5,2 & 4,70 & $-71,1$ & 12,2 & $-70,2$ & 12,1 & $-55,2$ & 20,9 \\
\hline \multirow[t]{3}{*}{8} & 6 & 5,23 & $-51,3$ & 10,1 & $-50,6$ & 9,9 & $-22,5$ & 10,2 \\
\hline & & & \multicolumn{6}{|c|}{ Rivet 3_w - measurement segment perpendicular to longer edge of } \\
\hline & & & \multicolumn{2}{|c|}{$90^{\circ}$ - radial } & \multicolumn{2}{|c|}{$90^{\circ}$ - radial } & \multicolumn{2}{|c|}{$0^{\circ}$ - circumferential } \\
\hline 1 & 0,4 & 1,48 & $-248,3$ & 25,4 & $-128,4$ & 14,2 & 33,4 & 19,6 \\
\hline 2 & 1,2 & 2,01 & $-113,7$ & 8,3 & $-124,4$ & 26,3 & $-8,2$ & 12,0 \\
\hline 3 & 2 & 2,55 & $-84,1$ & 15,0 & $-75,9$ & 19,2 & $-12,6$ & 14,9 \\
\hline 4 & 2,8 & 3,09 & $-82,1$ & 12,0 & $-81,0$ & 11,9 & $-26,4$ & 10,1 \\
\hline 5 & 3,6 & 3,62 & $-70,1$ & 10,2 & $-69,2$ & 10,1 & $-46,5$ & 13,1 \\
\hline 6 & 4,4 & 4,16 & $-82,8$ & 14,6 & $-81,7$ & 14,4 & $-40,7$ & 11,0 \\
\hline 7 & 5,2 & 4,70 & $-99,3$ & 9,5 & $-98,0$ & 9,4 & $-23,1$ & 13,9 \\
\hline \multirow[t]{3}{*}{8} & 6 & 5,23 & $-80,5$ & 7,2 & $-79,5$ & 7,1 & $-18,0$ & 9,9 \\
\hline & & & \multicolumn{6}{|c|}{ Rivet 6_l - measurement segment parallel to longer edge of specimen } \\
\hline & & & \multicolumn{2}{|c|}{$0^{\circ}$ - radial } & \multicolumn{2}{|c|}{$0^{\circ}$ - radial } & \multicolumn{2}{|c|}{$90^{\circ}$ - circumferential } \\
\hline 1 & 0,4 & 1,48 & $-319,9$ & 27,5 & $-175,8$ & 20,8 & 62,9 & 40,9 \\
\hline 2 & 1,2 & 2,01 & $-105,0$ & 28,1 & $-72,7$ & 35,2 & 47,9 & 15,3 \\
\hline 3 & 2 & 2,55 & $-107,1$ & 12,4 & $-105,7$ & 12,3 & 56,0 & 14,8 \\
\hline 4 & 2,8 & 3,09 & $-86,0$ & 16,2 & $-84,9$ & 16,0 & $-18,1$ & 8,6 \\
\hline 5 & 3,6 & 3,62 & $-81,6$ & 12,1 & $-80,5$ & 11,9 & $-0,6$ & 16,6 \\
\hline 6 & 4,4 & 4,16 & $-49,5$ & 12,5 & $-48,9$ & 12,3 & $-16,5$ & 8,7 \\
\hline 7 & 5,2 & 4,70 & $-50,2$ & 12,5 & $-49,6$ & 12,3 & 40,3 & 13,8 \\
\hline 8 & 6 & 5,23 & $-67,1$ & 17,0 & $-66,2$ & 16,8 & 29,9 & 14,4 \\
\hline & & & Rivet 6 & measur & $\begin{array}{r}\text { it segme } \\
\text { spe }\end{array}$ & $\begin{array}{l}\text { erpendic } \\
\text { en }\end{array}$ & ar to long & Ige of \\
\hline & & & $90^{\circ}$ & Idial & $90^{\circ}$ & dial & $0^{\circ}-\operatorname{circ}$ & rential \\
\hline 1 & 0,4 & 1,48 & $-265,3$ & 13 & $-261,8$ & 12,8 & $-24,8$ & 10,4 \\
\hline 2 & 1,2 & 2,01 & $-114,4$ & 8,7 & $-112,9$ & 8,6 & $-8,6$ & 15,6 \\
\hline 3 & 2 & 2,55 & $-84,9$ & 7,0 & $-83,8$ & 6,9 & $-12,3$ & 11,2 \\
\hline 4 & 2,8 & 3,09 & $-65,4$ & 9,7 & $-64,6$ & 9,6 & $-11,6$ & 8,8 \\
\hline 5 & 3,6 & 3,62 & $-53,5$ & 9,7 & $-52,8$ & 9,6 & $-35,7$ & 6,0 \\
\hline 6 & 4,4 & 4,16 & $-58,5$ & 12,3 & $-57,7$ & 12,2 & 4,9 & 7,8 \\
\hline 7 & 5,2 & 4,70 & $-66,7$ & 9,3 & $-65,8$ & 9,2 & $-17,6$ & 10,5 \\
\hline 8 & 6 & 5,23 & $-55,3$ & 13,8 & $-54,5$ & 13,6 & $-42,8$ & 11,1 \\
\hline
\end{tabular}




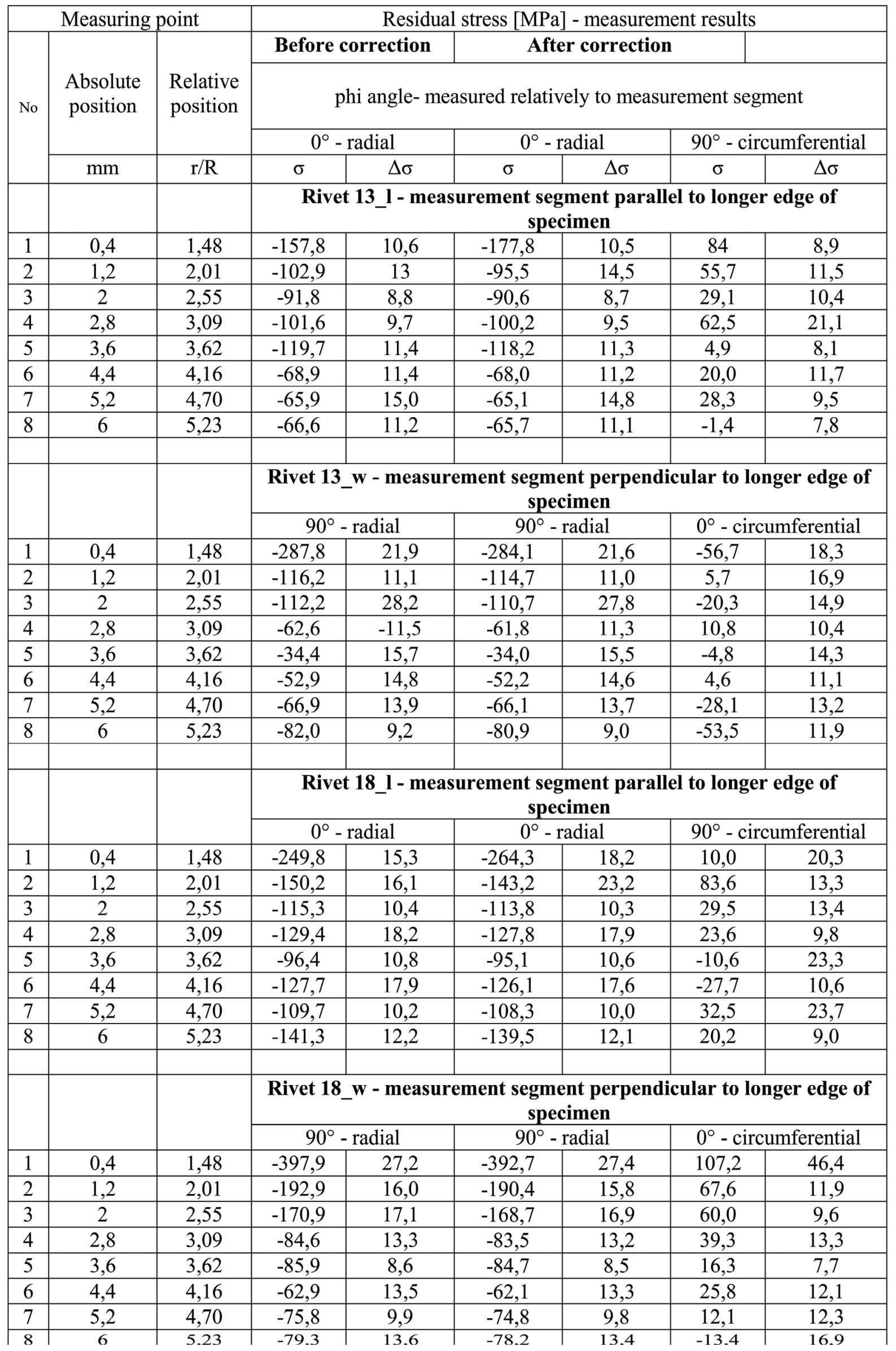




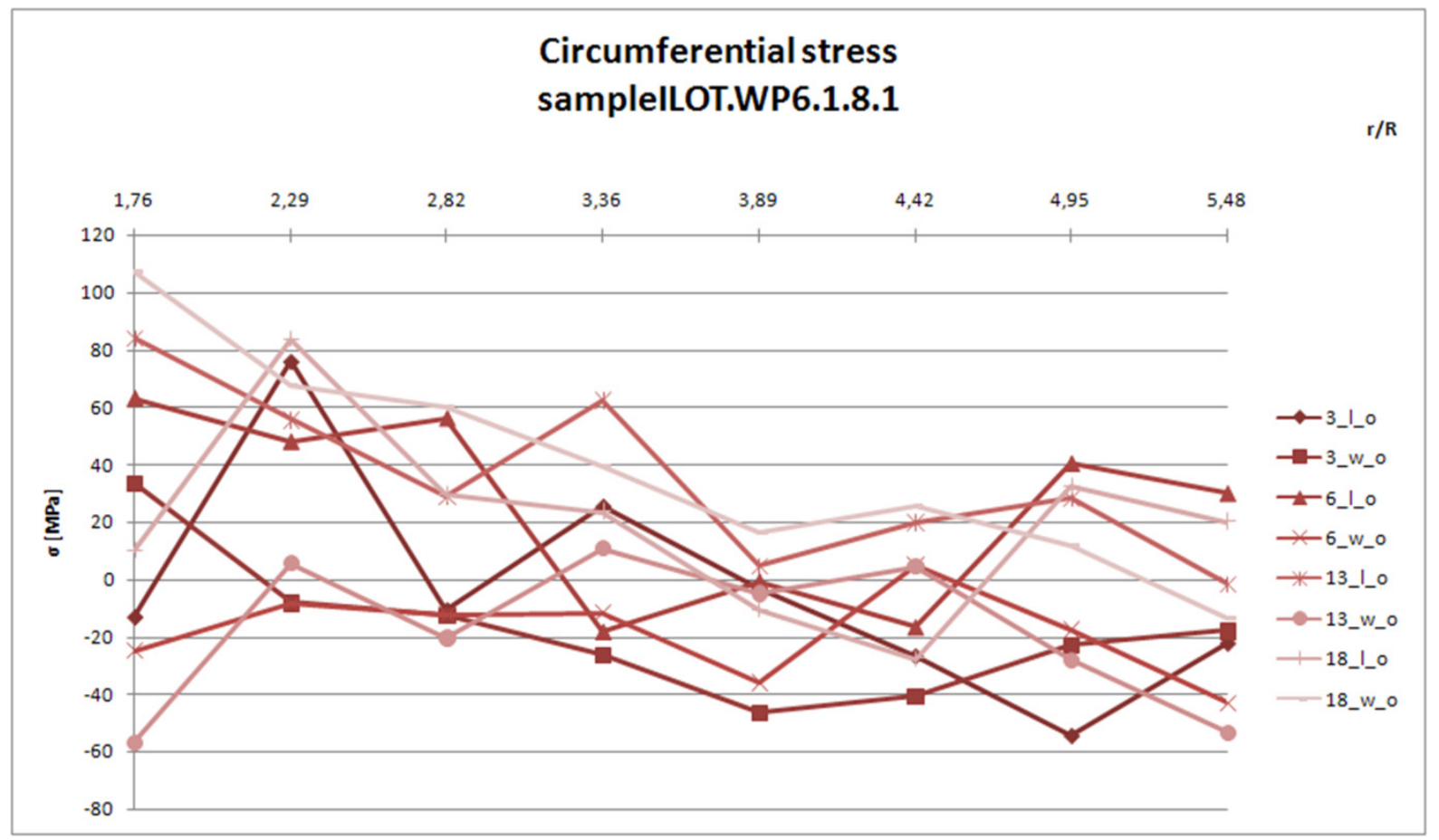

Signature: $\mathrm{x} \_\mathrm{y} \_\mathrm{z}$ : $\mathrm{x}$ - rivet number, $\mathrm{y}$ - 1: segment corresponding to rolling direction, w: segment perpendicular to rolling direction; $\mathrm{z}$ - p: radial stress, o - circumferential stress.

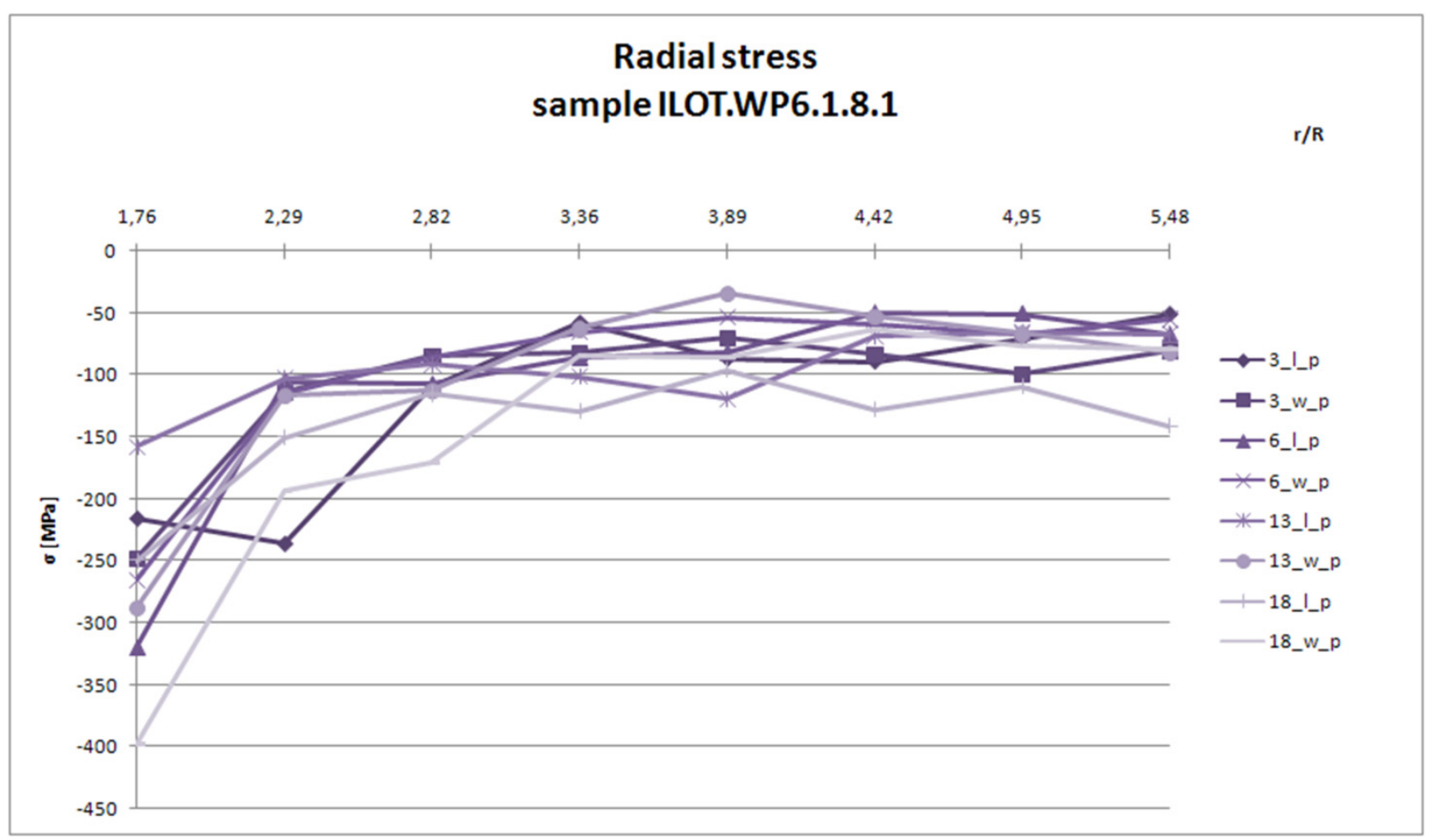

Signature: $\mathrm{x} \_\mathrm{y} \_\mathrm{z}$ : $\mathrm{x}$ - rivet number, $\mathrm{y}-1$ : segment corresponding to rolling direction, w: segment perpendicular to rolling direction; $\mathrm{z}$ - p: radial stress, o - circumferential stress.

Fig. 8. Residual stress course on the surface of aluminum plate in vicinity of driven head 


\section{MODELLING THE RIVETING PROCESS WITH FEM METHOD}

\subsection{Description of FE model}

The process of squeezing on the press was examined with the finite element method using 2D axisymmetric model with the MSC MARC/MENTAT and PATRAN software. The elements were the four-node Quad type. The model consists of two sheet plates and a rivet, and also the rigid surfaces (curves) that simulate the effects of the punch and hold-on (Fig. 9).

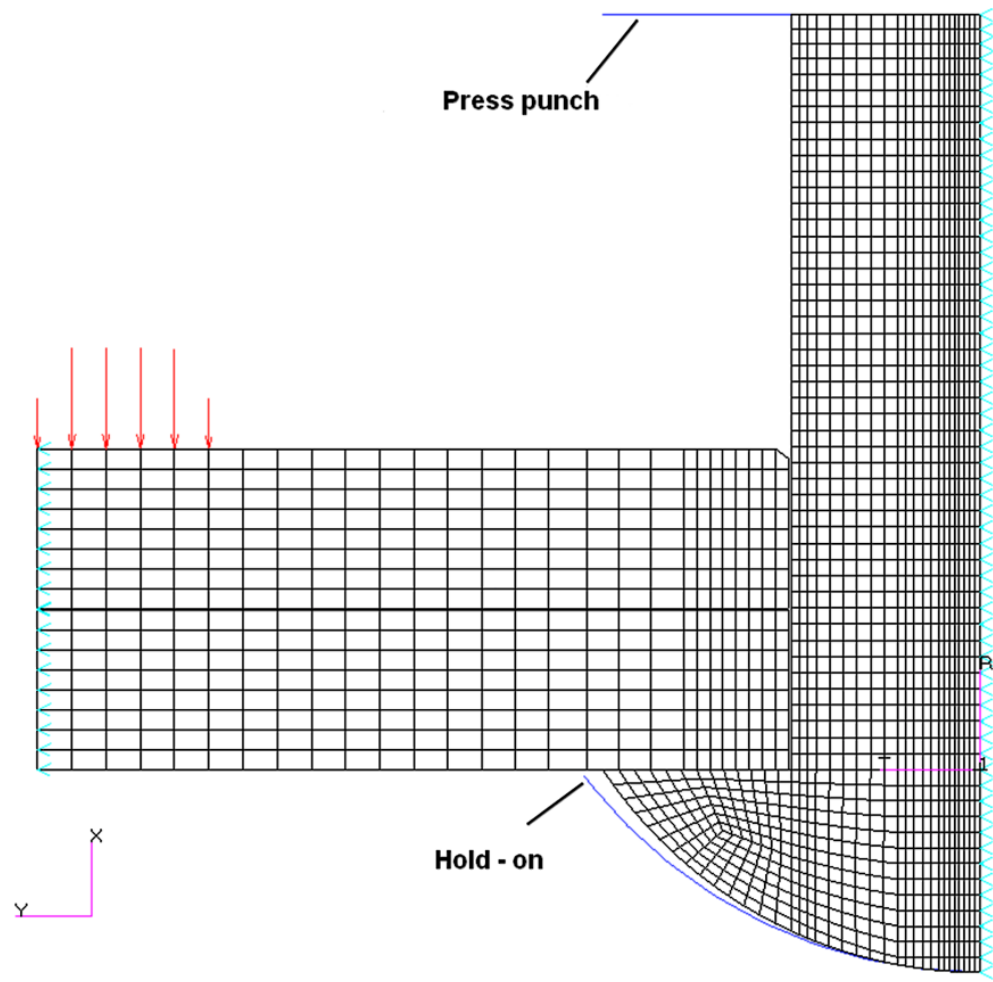

Fig. 9. FEM Model

These elements act on each other through the contact phenomena. The Coulomb friction model was used with the coefficient of friction equal to 0.2. For the sheet plates and the rivet, non-linear material models were adopted (Fig. 10), based on the research results at the AGH University of Science and Technology in Krakow (rivets) and the University of Technology and Life Sciences in Bydgoszcz. The actual values of stress and strain at characteristic points were determined on the basis of the engineering values, according to the algorithm described in [4].

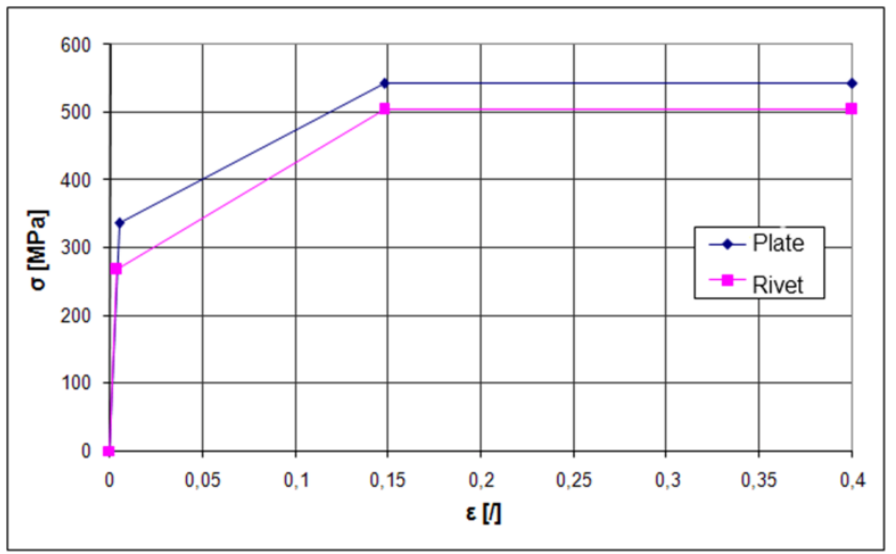

\begin{tabular}{|l|c|c|}
\hline \multicolumn{3}{|c|}{ Real values (calculated) } \\
\hline & plate & rivet \\
\hline$E$ & 68904,6 & 71687 \\
\hline $\mathrm{u}$ & 0,33 & 0,33 \\
\hline $\mathrm{R}_{\mathrm{e}}$ & 335,6 & 267,2 \\
\hline $\mathrm{R}_{\mathrm{m}}$ & 543,2 & 504,2 \\
\hline
\end{tabular}

Fig. 10. Material models used 
The hold-on remains motionless during the whole analysis. The press punch moves towards the bottom forming a driven head, then returns to the starting position. The amount of displacement of the press punch was selected so that to obtain the driven head diameters such as in the rivets around which the measurements were carried out.

The displacement in a radial direction was blocked for the rivet nodes lying on the axis (symmetry condition) and also for the nodes on the outer surface of the sheet plate, parallel to the rivet axis (which describes impact of non-modelled material sheets).

Riveting on the press is done with the riveting set (Fig.4b). It consists of the punch and the clamping sleeve. During riveting process, before the punch touches the rivet shank, plates are pushed together by the sleeve, which is coupled with the punch by a spring. To take this into consideration during the FEM analyses, the forces equal the one acting on the sleeve were applied to the nodes belonging to the surface of the inner material sheet (Fig. 9). The value of the force was based on the stiffness of the springs, the size of the rivet set and the height of the driven heads. The assumed course of the forces applied to the rivet set and press punch during the riveting process is shown in Fig. 11, which models the actual process.

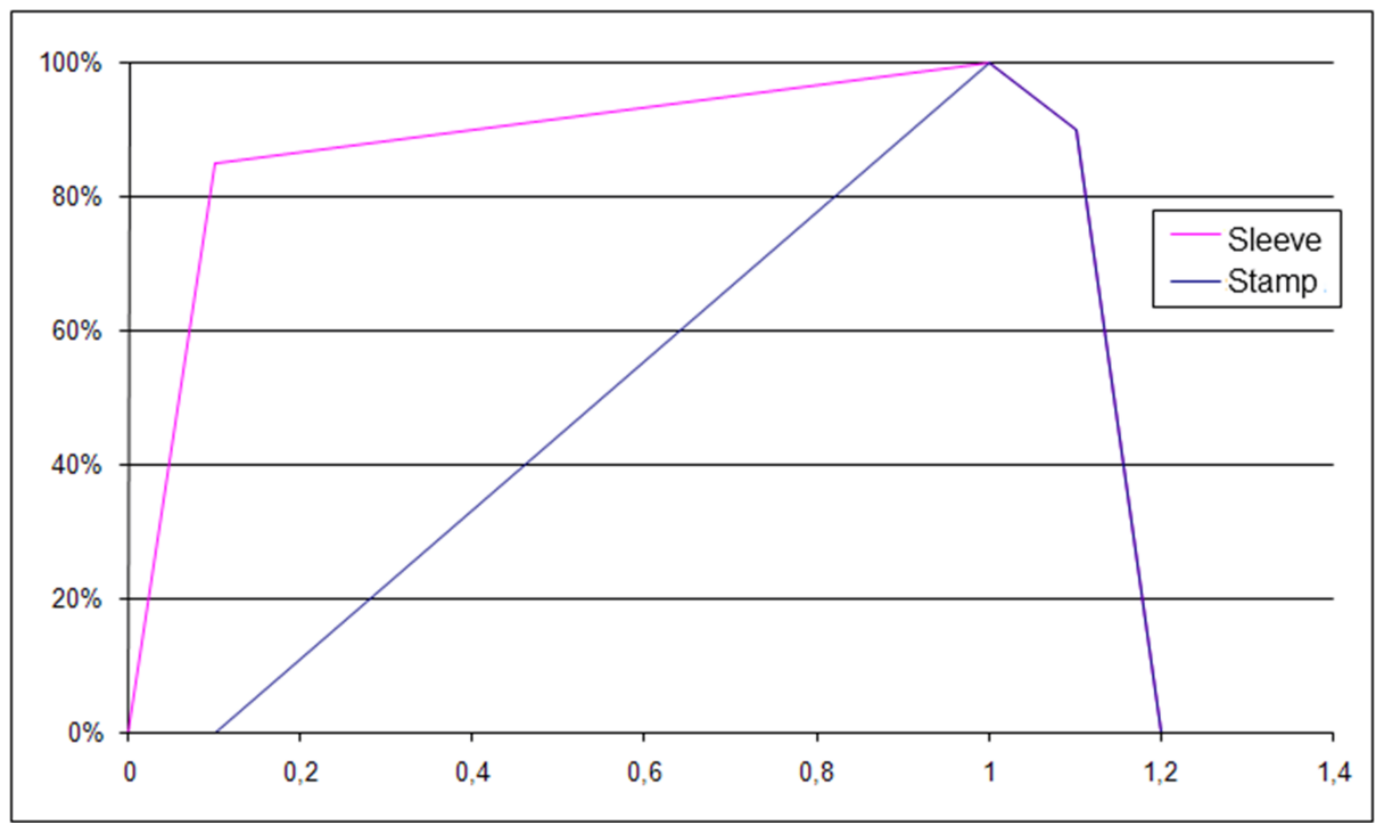

Fig. 11. Used squeezing force course shown on riveting tool and press stamp 1 - maximum pressure, 1.2 - press stamp and riveting tool withdraw

\subsection{The calculation results}

The shapes of the driven heads obtained during the analysis were correct and stress distributions were consistent with the expected ones. However, the squeezing force obtained during the calculation (analysis) was about 18\% lower (for the rivet No. 18) compared to the registered in the experiment. Below are stress images for the case corresponding to rivet No. 18 ( $\mathrm{D} / \mathrm{Do}=1.55)$. 

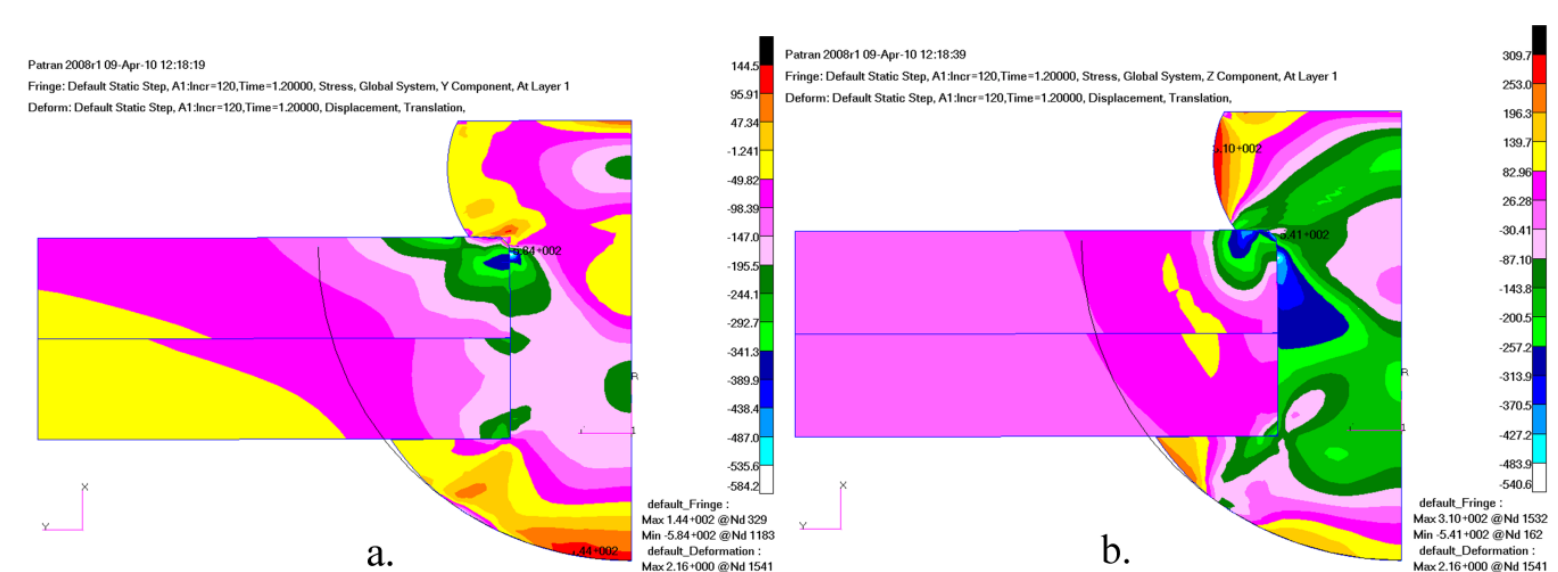

Fig. 12. Radial stress (a) and circumferential stress (b) after riveting
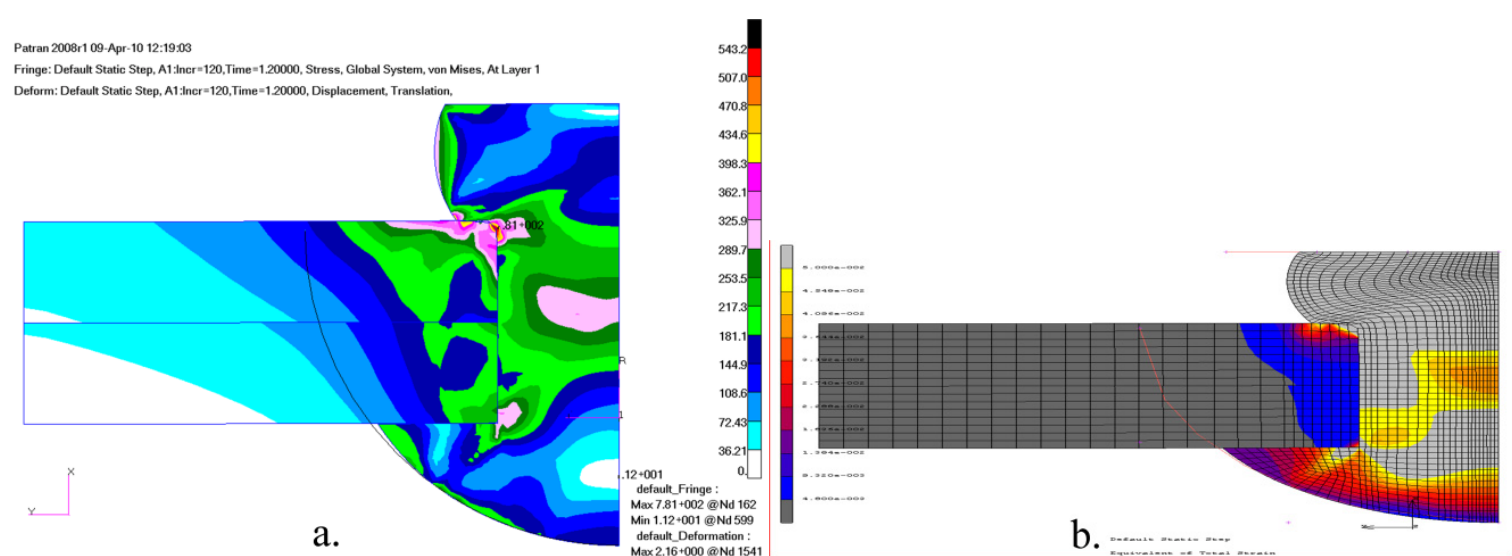

Fig. 13. Equivalent stress (Huber Mises Hencky) after riveting and aluminum plate strain

Figure $13 \mathrm{~b}$ shows the total strain when the press punch reaches its lowest position. Dark grey colour corresponds to the elastic deformation, light grey indicates deformation greater than $5 \%$. It is obvious that the plastically deformed area reaches far beyond the driven head (about $2.85 \mathrm{~mm}$ from the axis of the rivet, which is about 1.9 of the rivet radius). The X-ray diffractometric measurements are usually carried out for the elastic range. One measurement point is located in the plastically deformed area (for the rivet 18), for which the measurement may be affected by an error.

Figure 14 shows the course of radial and circumferential stress on the surface of the sheet plate, near the driven head, obtained from diffractometric measurements and FEM calculations, for the rivet 3 and 18 .
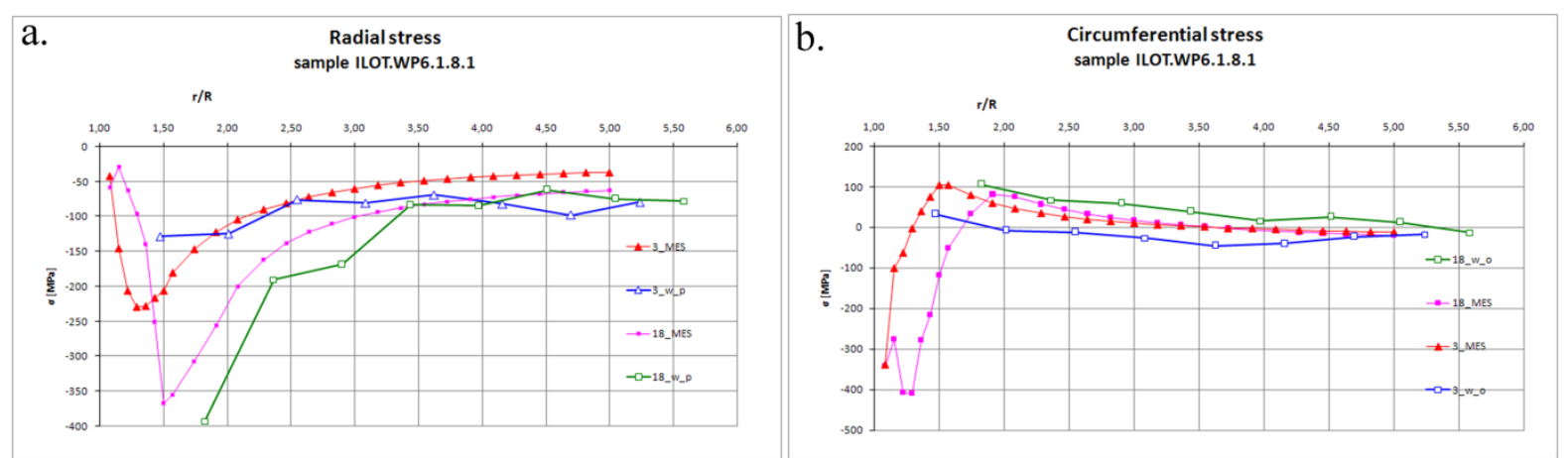

Fig. 14. X-ray diffractometric measurements and FEM simulation results 
Obtained during FEM analysis, the courses of radial and circumferential stress correspond to the results of X-ray diffractometric measurements. The obtained correspondence in the initial part of the graph is very high for the radial stress of rivet 3 . In the next parts of rivet 3 , the stress graph in the FEM model shows the compressive stress decreasing monotonically, while the X-ray diffractometric results graph rises slightly and at the last point is decreases again. For rivet 18, the courses of stress measured and calculated are similar, but the differences in values are significant in the first part of the chart and low for points lying further. Stress courses obtained in the calculations are smooth, while the curves derived from measurements have visible disorders. This may be due to the presence of residual stresses in the plate associated with the rolling and drilling holes (X-ray diffractometer measures the total stress) and also due to high relative measurements errors.

In the case of circumferential stresses, their courses obtained from measurements and FEM calculations are similar. However, in the measurement results for points located further from the axis of the rivet by more than doubled rivet radius $(r / R>2)$, the differences for the both rivets ( 3 and 18) are clear, which cannot be seen in the FEM calculations. The abnormalities are occurring at the beginning of the stress graph obtained from FEM calculation for rivet 18. This area is located under the driven head and disorders are related to the large deformation of the elements located there as well as due to the contact phenomena.

\section{SUMMARY}

The results obtained from FEM calculations are in high correspondence with the results of the experiment. It is worth noticing while the driven head diameter increases (squeezing force) the local extreme of stress (circumferential and radial) moves to the right of the graph. This stress course is consistent with the results of calculations presented in [1]. This extreme is located at the border or outside the measurements range (zone). Experimental verification of the obtained results is still needed.

The FEM model is still being improved mainly in order to obtain a better correspondence to the experimental squeezing force. Also, the X-ray diffractometric measurement methodology is still under development. Besides that, the stress measuring gauge experiment is under preparation to obtain stress measurements in the immediate vicinity of the rivet hole.

\section{AKNOWLEDGEMENTS}

The financial support from Ministry of Science and Higher Education under the contract No. 59/EUR/2006/02 is gratefully acknowledged.

\section{REFERENCES}

[1] Müller, R., P., G. (1995). An Experimental Investigation on the Fatigue Behavior of Fuselage Riveted Lap Joints; The Significance of the Rivet Squeeze Force, and a Comparison of 2924$T 3$ and Glare 3. Praca doktorska, Delft University of Technology, Universitatdrukkerij, Delft.

[2] Mruk, Z. (2008). Riveting process for specimen used in durability tests of riveted joint made with rivets closed with force control and axial strain measure. INSTRUCTION. (in polish). PZL Mielec. (Internal Report 1/DRG-6/42/2008)

[3] Skorupa, M., Skorupa, A., Machniewicz, T., Korbel, A. (2009). An Experimental Investigation on the Fatigue Performance of Riveted Lap Joints. In: M. J. Bos (Eds.), ICAF 2009, Bridging the Gap between Theory and Operational Practice. Proceedings of the 25th Symposium of the International Committee on Aeronautical Fatigue, Rotterdam, The Nederlands, 27-29 May 2009.

[4] MSC Marc Documentation, Volume A: Theory and User Information. MSC Corp. 2008. 